\title{
Clasificación e inventario de humedales en cuencas fluviales: caso del arroyo Yaguarí, noreste de Argentina
}

\author{
Leticia Rodríguez $^{(1)}$, Carlos Ramonell(1), Daniela García(1), Emiliano Veizaga(1), Silvio Graciani ${ }^{(1)}$, \\ Alejandro Giraudo ${ }^{(2)}$, y Enrique Mihura ${ }^{(1)}$ \\ (1) Facultad de Ingeniería y Ciencias Hídricas, Universidad Nacional del Litoral. Ciudad Universitaria - Paraje "El Pozo" \\ (3000) Santa Fe, Argentina. \\ leticia@fich.unl.edu.ar; cgramonell@yahoo.com.ar; mariadaniela_garcia@hotmail.com; veizaga.e82@gmail.com; \\ sgraciani@gmail.com; emihura@fich.unl.edu.ar \\ (2) Instituto Nacional de Limnología- Universidad Nacional del Litoral-Consejo Nacional de Investigaciones Científicas y \\ Técnicas, Ciudad Universitaria - Paraje “EI Pozo" (3000) Santa Fe, Argentina.
}

alejandrogiraugo@gmail.com

\begin{abstract}
RESUMEN
En preparación para el inventario nacional de humedales, la Secretaría de Medio Ambiente y Desarrollo Sustentable de Argentina definió sitios pilotos para su caracterización y propuestas metodológicas de clasificación. Se sintetizan aquí los resultados obtenidos en la cuenca fluvial del arroyo Yaguarí, Corrientes, considerada piloto debido a la actividad antrópica: cultivo de arroz y ganadería sobre pasturas implantadas que impactan sobre los humedales naturales. La identificación de los tipos de humedal se realizó a partir del análisis de antecedentes, la interpretación visual de imágenes satelitales, la identificación de momentos hidrológicos húmedos, y la identificación por observación directa del humedal en campo. Estos aspectos fueron integrados para definir los tipos de humedales utilizando una clasificación simple, jerárquica y abierta, establecer la extensión espacial de los mismos, y caracterizar sus rasgos distintivos a escala del terreno. Los elementos de la estructura jerárquica seleccionada son: Ambiente-Región-Sistema-Unidad-Elemento. El ambiente es continental y la región pertenece al Corredor Fluvial Chaco-Mesopotámico. Se identifican sistemas antrópicos (unidades: tajamares, arroceras, embalses para riego) y sistemas fluviales (unidades: planicies de inundación, cabeceras de tributarios menores). Como elementos se encuentran bosques en galería, pantanos tras-albardón, cárcavas, paleocauces, manantiales y cauces. La metodología desarrollada puede replicarse en cuencas de características similares de modo de contar con herramientas para el inventario, la evaluación y el manejo de los humedales del país.
\end{abstract}

Palabras clave: clasificación de humedales, influencias antrópicas, geomorfología, arroyo, aluvial.

\section{Wetland classification and inventory in fluvial basins: the case of the Yaguari creek, North-Eastern Argentina}

\begin{abstract}
In preparation for the National Wetland Inventory, the Secretary for the Environment and Sustainable Development of Argentina defined pilot cases for their characterization and suggested methodologies for their classification. The results obtained on the pilot site of $A^{\circ}$ Yaguari fluvial basin, Corrientes, are synthesized and presented in this paper. It is considered a pilot site due to the increasing anthropic activities: rice cultivation/ irrigation and cattle grazing over implanted pastures that impact the natural wetlands. The identification of the types of wetlands was accomplished through the analysis of background information, visual interpretation of satellite images, identification of wet hydrologic periods, and wetland identification by direct field observation and reconnaissance. All these aspects were integrated to define the wetland types using a simple, hierarchical and open classification system, to establish the areal extent of the wetlands, and characterize their distinctive features at field scale. The elements of the selected hierarchical structure are: Ambient-Re-
\end{abstract}


gion-System-Unit-Element. The ambient is continental, and the region belongs to Chaco-Mesopotamic Fluvial Corridor. Anthropogenic systems (units: ponds, rice fields, irrigation water reservoirs), and fluvial systems (units: floodplains, minor tributaries headwaters) are identified. The elements that can be found are: riparian forests, marshes behind river banks, ditches, paleo-channels, springs and riverbeds. The developed methodology can be replicated in similar basins using these tools for the inventory, evaluation and management of Argentinean wetlands.

Keywords: wetland classification, anthropogenic impact, geomorphology, creek, alluvial.

\section{Introducción}

Los mapas de humedales constituyen un pre-requisito para el inventario de humedales y el manejo, protección, y restauración de estos ambientes (Wilen et al., 1996). A nivel internacional existe un variado historial acerca del desarrollo de inventarios nacionales de humedales, sin embargo, el grado de avance difiere según las regiones y países. Algunos ejemplos son la iniciativa de humedales mediterráneos MedWet (Costa et al., 1996), el inventario de humedales de Asia que tomó como base el sistema de clasificación propuesto por Scott (1989) (Finlayson et al., 2001), el inventario nacional de humedales de los Estados Unidos (Cowardin et al., 1979), el inventario nacional de México (CONACYT-CONAGUA, 2012) y el de Brasil (Junk et al., 2014), el inventario de humedales de la provincia de Queensland, Australia (https://wetlandinfo.ehp.qld.gov.au/wetlands), el Inventario Español de Zonas Húmedas-IEZH a escala 1:50000 elaborado en 2012 y actualizado en 2014 (MITECO, 2019).

Cada país (o región) o bien adhiere a uno de los sistemas de clasificación e inventario como el de Cowardin et al. (1979), Davis (1994), Brinson (2008), entre otros, o adopta elementos complementarios de varios métodos a fin de adaptarlos a su diversidad de ambientes. Una característica común de varios sistemas de clasificación es su estructura jerárquica definida en base a aspectos geomorfológicos, hidrológicos y bióticos que caracterizan a los humedales.

Debido a su gradiente latitudinal, topográfico y climático, Argentina cuenta con una gran variedad y cantidad de humedales, que albergan una notoria biodiversidad, cumplen funciones ecosistémicas variadas, proveen bienes y servicios para el bienestar humano, y resguardan la fauna y flora silvestres e importantes muestras del patrimonio cultural, arqueológico e histórico del país. A pesar de ello, aún no existe legislación nacional que establezca las pautas para la conservación, protección y uso racional y sostenible de los humedales.

No obstante, desde hace varios años, la Secretaría de Ambiente y Desarrollo Sustentable de la Nación-SAyDS lleva a cabo diversas acciones con el fin de generar información de calidad para asegurar la conservación y el uso racional de los humedales en el contexto del calentamiento global y los cambios acelerados en el uso del suelo que ha experimentado la Argentina en las últimas décadas (Benzaquén et al., 2013, 2017).
Así, la SAyDS está avanzando en la realización de un Inventario Nacional de Humedales, que comprende diferentes niveles o escalas de detalle: a) Nivel 1: Regiones y Subregiones de humedales, identificables a escalas menores a 1:1000000; b) Nivel 2: Sistemas y Subsistemas de Humedales, discernibles a escalas entre 1:500000 a 1:100000; y c) Nivel 3: Unidades de humedales, donde la escala de trabajo es mayor que 1:100000 (Benzaquén et al., 2013). Uno de los estudios realizados por la SAyDS comprendió el mapeo del país para identificar y caracterizar regiones y subregiones de humedales (Benzaquén et al., 2017) en Nivel 1. Estudios de Nivel 2 fueron realizados en el Corredor Fluvial Paraná-Paraguay (Benzaquén et al., 2013).

En ese marco, este trabajo presenta la estructura de clasificación y el modelo de inventario realizado en un sitio piloto seleccionado por la SAyDS para su Inventario Nacional, atendiendo a los usos antrópicos de su entorno y la potencial amenaza que representan para los ecosistemas de humedal. El caso de estudio es la subcuenca del $A^{\circ}$ Yaguarí, en el noreste subtropical argentino, una cuenca fluvial típica, que posee un colector principal con una planicie de inundación asociada, cursos tributarios de diferentes órdenes y las cabeceras de estos, en las que suele haber aguas surgentes estacionales. Así, existen en la cuenca humedales areales, lineales y puntuales, a los que se suman diversos humedales antrópicos, asociados principalmente a explotaciones arroceras y pecuarias.

El objetivo general del trabajo fue proporcionar elementos que contribuyan a preparar y refinar la metodología para inventariar los humedales del país, y consolidar una herramienta de evaluación del recurso a nivel nacional, destinada a ser un instrumento de apoyo a los planes y programas de conservación y/o protección de humedales. A fin de cumplir el objetivo se realizó un intenso trabajo cartográfico y de procesamiento de imágenes satelitales para la identificación y el mapeo de humedales, cuyo resultado fue volcado a un Sistema de Información Geográfica. Ese resultado fue verificado en campo, donde se llevó a cabo el reconocimiento de humedales, su emplazamiento, flora y fauna; y toma de muestras de suelo y aguas (analizadas luego en laboratorio). El trabajo cartográfico y de campo fue apoyado con el análisis de antecedentes, y de metodologías de inventarios aplicadas en otros países. Finalmente se elaboraron fichas técnicas de caracterización y clasificación de cada tipo de humedal identificado. 


\section{Antecedentes}

Mitch y Gosselink (2000) reconocen al régimen hidrológico como el principal factor condicionante de las propiedades estructurales y funcionales de los ecosistemas de humedales. En este sentido, el Servicio de Pesca y Vida Silvestre de Estados Unidos, a cargo del inventario nacional de humedales de ese país, utilizó el sistema de clasificación propuesto por Cowardin et al. (1979), basado en una estructura jerárquica que reconoce progresivamente diferentes niveles de complejidad: un nivel general de sistemas y subsistemas, y luego niveles más desagregados que incluyen clases, subclases y tipos dominantes definidos en base al régimen hídrico, la química del agua y los suelos. Para Cowardin et al. (1979), un sistema se refiere a un conjunto de humedales y hábitats de aguas profundas que comparten la influencia de factores hidrológicos, geomorfológicos, químicos y biológicos similares. Cada sistema se desagrega en subsistemas definidos en término de la permanencia de agua, gradientes hidráulicos, velocidad del agua, características del sustrato, y extensión del valle de inundación. Cada subsistema tiene una flora y fauna características. El nivel más detallado en la estructura jerárquica lo constituyen las clases, establecidas según las características del lecho/fondo del humedal.

Brinson (1993) introdujo la clasificación hidrogeomórfica, que hace hincapié en los atributos geomor- fológicos e hidrológicos, y no solo en la clasificación biótica. Las entradas y salidas de agua definen los sistemas de humedales; posteriormente, la presencia o ausencia de agua da como resultado el hábitat de este.

El Instituto Nacional de Ciencia e Tecnología em Áreas Ümidas, conjuntamente con otras instituciones de Brasil están aportando al inventario nacional de humedales de Brasil (Junk et al., 2014). La metodología de clasificación adoptada posee una estructura jerárquica, y considera la hidrología como el factor condicionante de las características de un humedal, por lo tanto, es prioritaria en la metodología. Si bien no considera elementos como suelos hídricos o el emplazamiento hidrogeomórfico, en la denominación de niveles y subniveles, guarda similitud a la metodología propuesta por Cowardin et al. (1979).

Otra reciente experiencia latinoamericana es la colombiana acerca de un Sistema nacional de clasificación de humedales desde una perspectiva científi$\mathrm{ca}$, que se basa en un enfoque ecológico construido sobre los conceptos de pulsos de crecidas y emplazamiento hidrogeomórfico (Ricaurte et al., 2019). EI enfoque es similar al brasilero, adaptado a la topografía y diversidad colombiana, la clasificación es jerárquica, multi-escala, funcional, y organizada de acuerdo a cuatro niveles: sistema, macro-región, subsistema y clase.
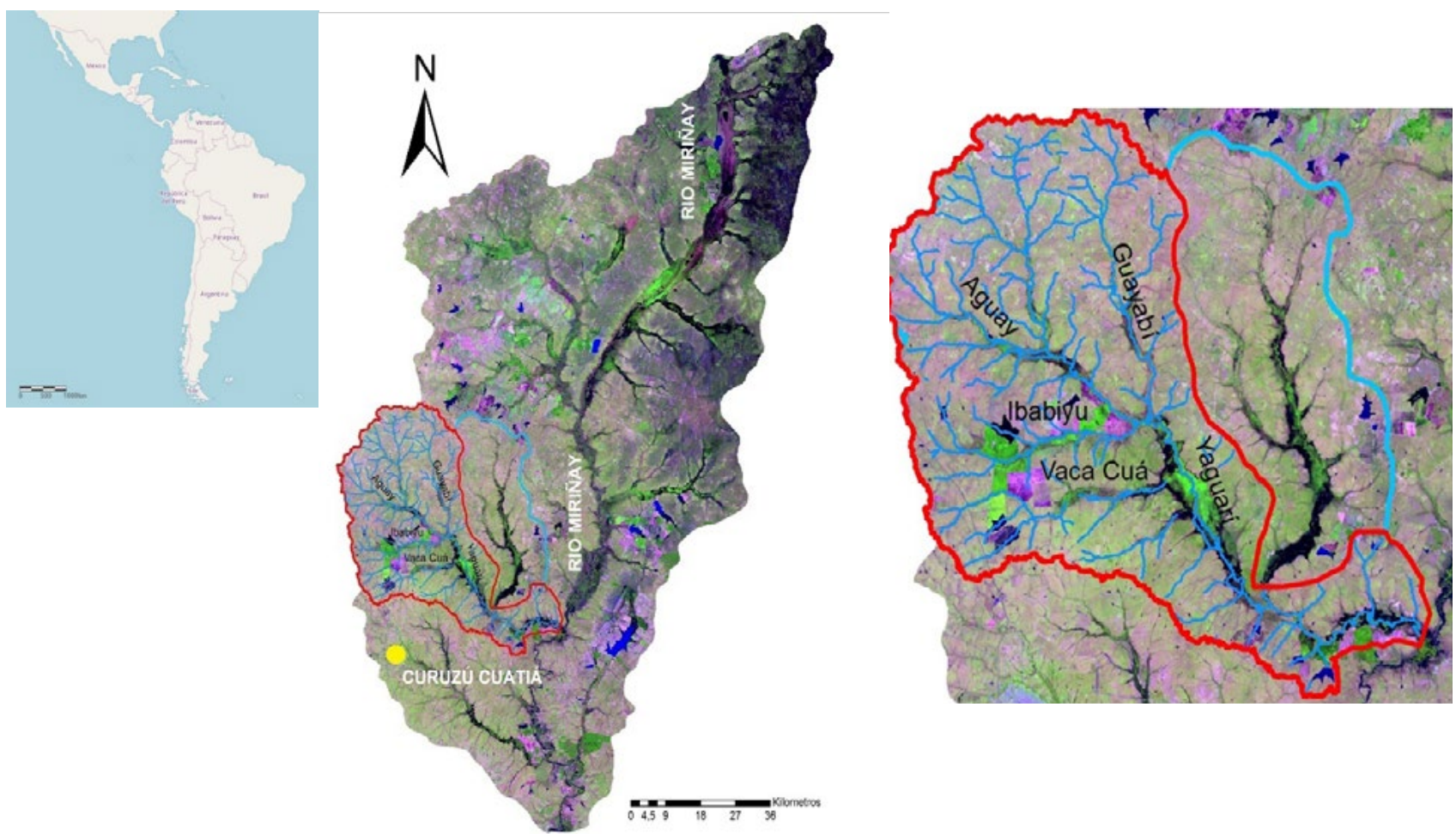

Figura 1. Ubicación del área de estudio.

Figure 1. Study area location (Map of Argentina obtained from http://www.ign.gob.ar). 


\section{Caracterización de la zona de estudio}

La cuenca del $A^{\circ}$ Yaguarí, tributario del río Miriñay, está ubicada en el Centro-Sur de la provincia de Corrientes, Argentina (Fig. 1). Este trabajo incluyó la porción de la cuenca que comprende al $A^{\circ}$ Yaguarí y a sus afluentes por margen derecha: $A^{\circ}$ Guayaibí, $A^{\circ}$ Aguay, $A^{\circ}$ Ibabiyú y $A^{\circ}$ Vaca Cuá (Fig. 1), que comprenden un área de drenaje de $1571 \mathrm{~km}^{2}$.

La precipitación media anual alcanza $1415 \mathrm{~mm}$ (serie 1991-2010), con extremos anuales pronunciados caracterizados por máximos de más de $2250 \mathrm{~mm}$ y mínimos de $900 \mathrm{~mm}$. La ETP media anual para dicho período es $1540 \mathrm{~mm}$ (FICH, 2017). Se pueden presentar déficits en verano y excesos en otoño y primavera.

La zona de estudio ocupa el sector más elevado de la provincia de Corrientes, con un rango de alturas comprendido entre $130 \mathrm{~m}$ y $60 \mathrm{~m}$. Una rica red de cursos fluviales corta las planicies preexistentes labradas en materiales fluvio-lacustres plio-pleistocenos. El relieve dominante es de lomadas amplias, convexas o con divisorias planas subhorizontales, resultado de la incisión de cauces organizados en una red de drenaje de tipo angular, principalmente, controlado por la presencia de vulcanitas jurásicas y sedimentitas cretácicas aflorantes o sub-aflorantes; completan estos elementos básicos una planicie sedimentaria entre los ríos Miriñay y Aguapey y una terraza de origen fluvial sobre el río Uruguay. Los suelos dominantes son arcillosos, con predominio de arcillas expandibles (INTA, 2001).

\section{Geología y Geomorfología}

Geológicamente, la provincia de Corrientes se encuentra ubicada en una región de transición entre las cuencas Chacoparanense y de Paraná. Ambas cuencas suman más de $1.400 .000 \mathrm{~km}^{2}$. El relleno de rocas ígneas y sedimentarias en Corrientes apenas alcanzan

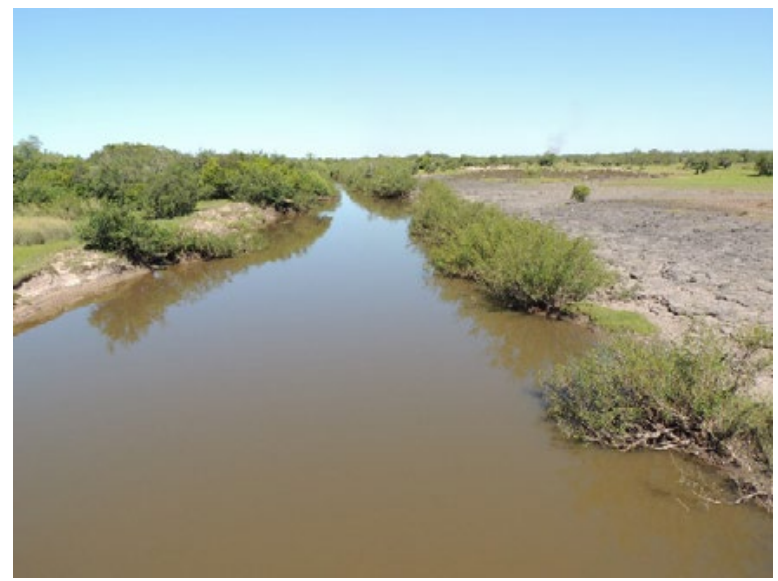

los $4000 \mathrm{~m}$ de espesor, con un promedio inferior a $2000 \mathrm{~m}$, incluyendo un registro sedimentario con depósitos desde el Paleozoico hasta la actualidad (Mira et al., 2015).

Los afloramientos más frecuentes en la cuenca del $\mathrm{A}^{\circ}$ Yaguarí corresponden a la Fm. Solari y a la Fm. Serra Geral (Herbst y Santa Cruz, 1985), del Mesozoico. La Fm. Serra Geral identifica a basaltos dispuestos en coladas horizontales de pocas a varias decenas de metros, filones capa y diques. Sus colores van del pardo rojizo a grisáceo y negro, presentando minerales secundarios como zeolitas, calcita y calcedonia. La unidad está fuertemente diaclasada, y aflora en el lecho de cursos de agua constituyendo, además, la base dominante del paisaje, en la que están labradas las geoformas mayores, i.e., valles fluviales. Los afloramientos de vulcanitas constituyen un condicionante estructural de la traza de la red de drenaje (Fig. 2-izquierda).

La Fm. Solari, de distribución más reducida que los basaltos entre cuyas coladas se intercala y se sobrepone, es bastante homogénea. Está constituida por areniscas de color amarillento, rosadas y rojizas, bien seleccionadas y finamente laminadas, con estratificación cruzada. Las areniscas son cuarzosas con una matriz de óxidos férricos y arcillas caoliníticas (Fig. 2-derecha).

Los valles fluviales de la cuenca del $A^{\circ}$ Yaguarí disectan parcial o totalmente las unidades geológicas referidas previamente, y otras de menor antigüedad sobreimpuestas. En sus fondos se reconocen depósitos de cauce y de inundación, además de otros coluviales hacia las cabeceras, que constituyen fondos planos de valle, a veces con un nivel de terraza. Estos sedimentos forman el sustrato de los humedales naturales del área, y carecen de denominación estratigráfica formal.

El patrón de drenaje de la cuenca posee un diseño general angular, con terminaciones subdendríticas en

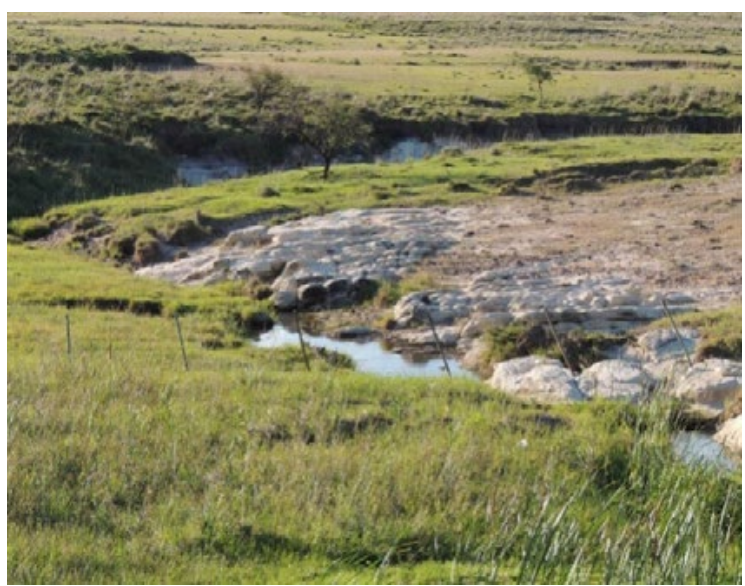

Figura 2. Izquierda. Afloramientos de la Fm. Serra Geral en la margen derecha del $\mathrm{A}^{\circ}$ Yaguarí Derecha: Cauce sobre lecho de areniscas aflorantes de la Fm. Solari.

Figure 2. Left: Outcrop of Serra Geral Formation on the right bank of the Yaguari Creek. Right: water course flowing onto sandstone outcrop. 
las cabeceras de los tributarios del noroeste, y en enrejado-rectangular, en los cursos de menor orden del resto de la subcuenca. Los patrones más extendidos arealmente, esto es el angular y el enrejado/rectangular, reflejan el control por fracturamiento de las rocas mesozoicas.

El colector principal de la subcuenca es un curso de $5^{\circ}$ o $6^{\circ}$ orden siguiendo la nomenclatura de Strahler (1957), con una densidad de drenaje elevada. Las zonas de interfluvio tienen gradientes bajos, con divisorias de agua ampliamente convexas o planas horizontales. Los fondos de valle suelen ser planos y horizontales, pero por agradación de sedimentos, normalmente en los valles de orden 2 y superiores de la red. Se trata de sedimentos clásticos finos, desde netamente arenosos a exclusivamente arcillosos. Estos sedimentos son coluviales en las cabeceras de las cuencas (originados en la reptación del manto de meteorización), y fluviales (de planicies de inundación, predominantemente), en los cursos de orden $3 y$ mayores. En algunos valles existe un nivel de terraza fluvial, con depósitos fluviales antiguos además de los recientes o actuales.
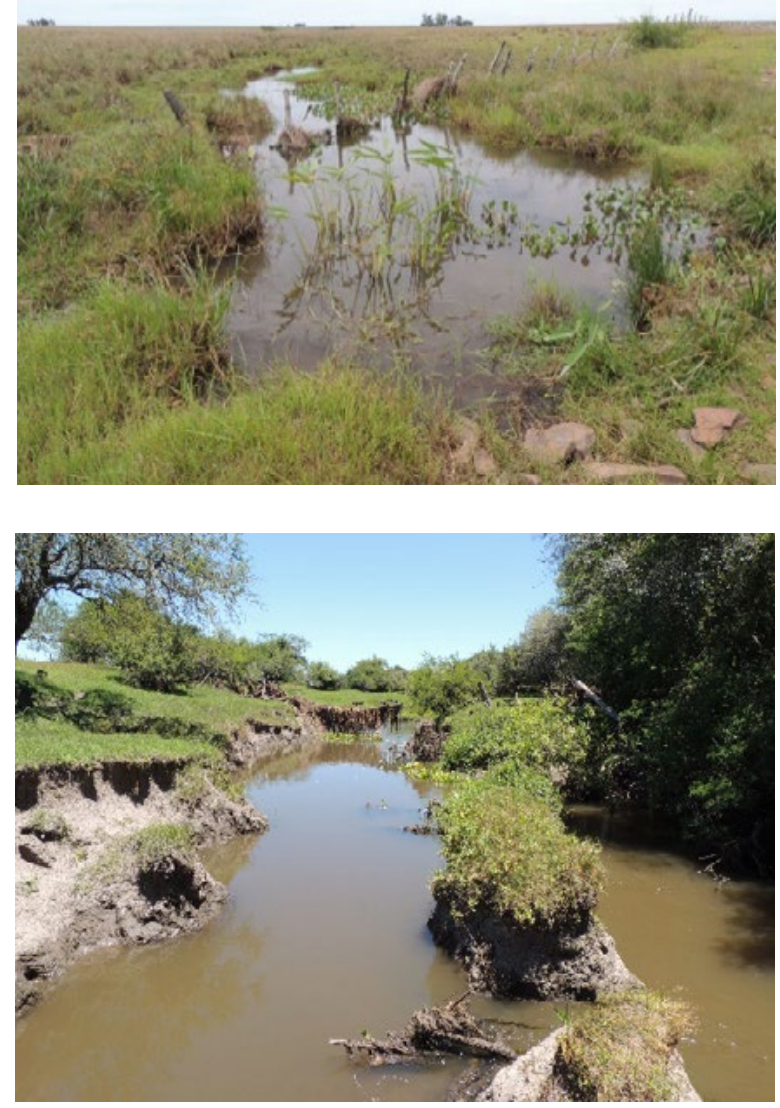

Los sedimentos de fondo de valle son de coloración y coherencia variada: pardo-rojizos a negros, y sueltos a resistentes. Su espesor puede alcanzar algunos metros, sin cubrir completamente a las rocas mesozoicas en el lecho y márgenes de los cauces, que aparecen de manera saltuaria. Los valles de orden 1, 2 y ocasionalmente los de orden 3 de la cuenca carecen de planicies aluviales de inundación (Fig. 3A). Incluso en valles de orden 1 y 2 suelen no existir cauces activos, albergando humedales en los materiales detríticos finos de sus fondos planos alimentados desde el nivel freático; si existen cauces, son de dimensiones decimétricas, con márgenes erosivas de talud vertical a modo de cárcavas. Al aumentar el orden del valle los cauces presentan una estrecha franja inundable o de mayor cantidad de agua subsuperficial donde se desarrollan bosques en galería (Fig. 3B).

Algunos cursos mayores tributarios del $\mathrm{A}^{\circ}$ Yaguarí poseen sus cauces discontinuados por tramos, debido a la presencia de tajamares, que son construcciones antrópicas para la acumulación de agua de uso ganadero en la región, de antigüedad más que centenaria. En cuanto a planicies de inundación, la más desarrolla-
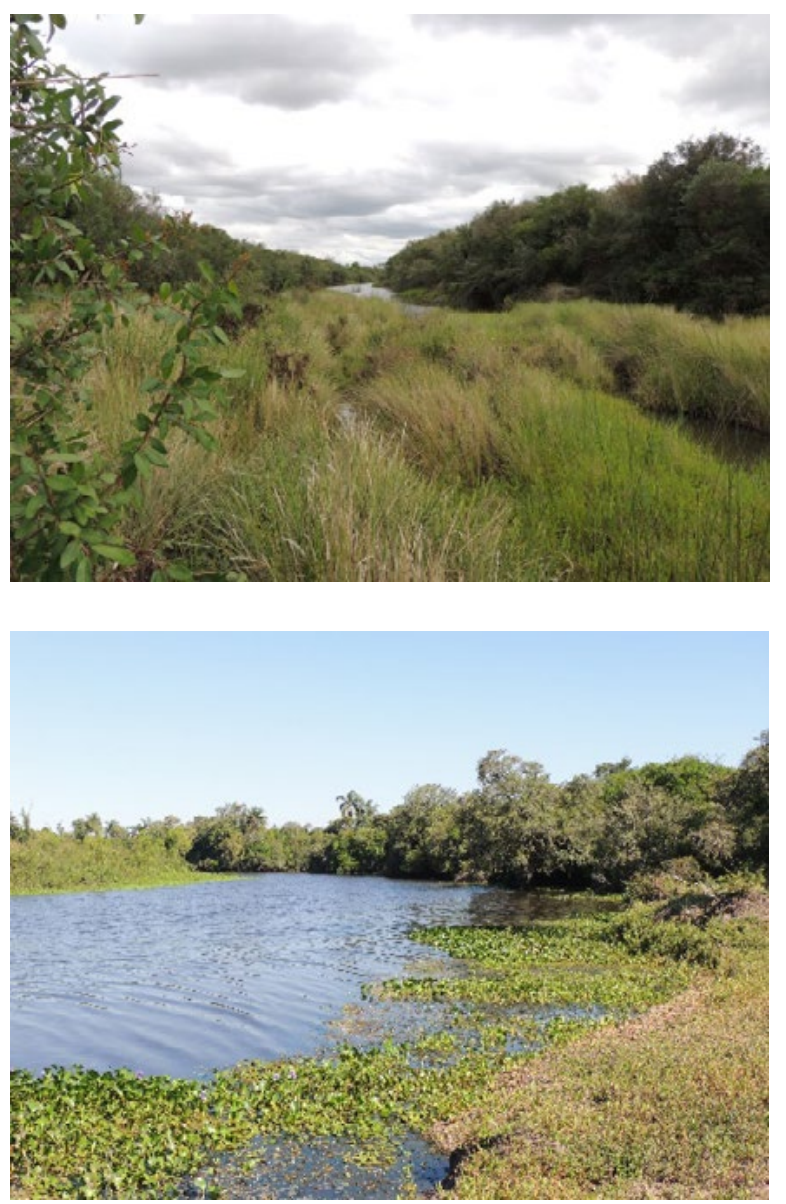

Figura 3. A: humedal de cabecera en tributario de orden 1-2; $B$ : bosques en galería en terraza y humedales en cauce del $A^{\circ}$ Sauce; $\mathrm{C}$ procesos erosivos y humedales en el $A^{\circ}$ Vaca Cuá; $D$ : humedal en planicie de inundación $A^{\circ}$ Yaguarí.

Figure 3. A: wetland at the headwater of a 1st-2nd order tributary; B: riparian forest along the terrace and riverbed wetland on the Sauce Creek; C: erosive processes and wetlands on the Vaca Cuá Creek; D: wetland on the floodplain of the Yaguarí Creek. 
da es la del propio $A^{\circ}$ Yaguarí en su tramo medio que constituye el principal humedal natural del área, habida cuenta su extensión y diversidad de biota (Fig. 3D).

Tanto aquí como en los fondos planos de tributarios de mayor orden, los patrones morfológicos dominantes de los cauces son el recto (Fig. 4A) y el meandriforme (Fig. 4B); el patrón recto se asocia bien al abandono de meandros, o bien a la presencia de rocas fracturadas en el lecho o el subálveo inmediato. En los subtramos meandriformes los cauces tienen ancho regular y meandros consecutivos de dimensiones variadas, sinuosidad irregular y localmente alta, lo cual es característico de planicies con abundancia de materiales finos, cohesivos.

Las planicies de inundación poseen pocos elementos geomorfológicos que constituyen elementos de humedal, siendo los más extendidos los pantanos y áreas de tras-albardón, y los segmentos de cauce abandonados por rectificación de meandros, en segundo lugar. Estos tienen dimensiones reducidas en comparación con los anteriores, pueden alojar

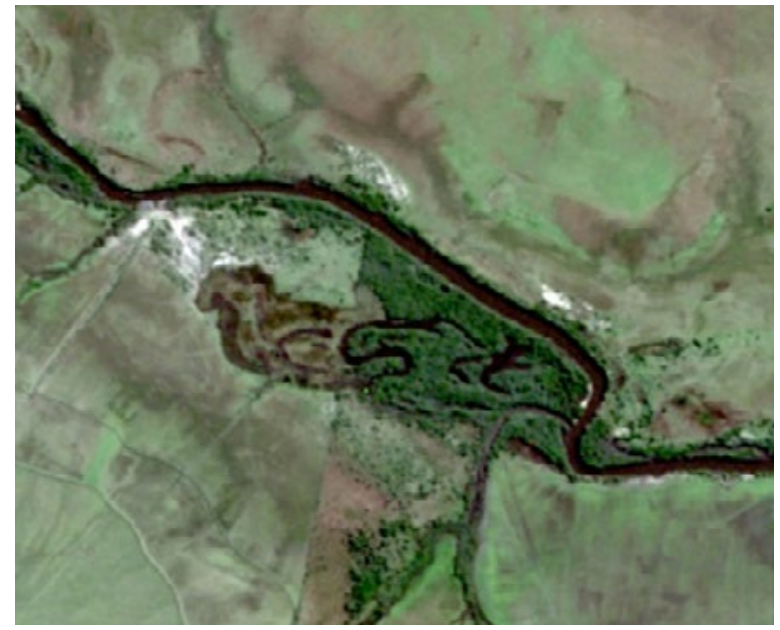

de lluvia y aportes de aguas freáticas, tanto en las zonas más elevadas cercanas a afloramientos rocosos como en zonas bajas con freática cercana a la superficie. La magnitud y distribución de su caudal no se conoce, sino que se infiere a partir de información indirecta. En la cuenca del $A^{\circ}$ Yaguarí no existen estaciones hidrométricas cuya información permita analizar la estacionalidad y los pulsos de su régimen hídrico. Tampoco existen perforaciones o sondeos dado que el abastecimiento de agua proviene de fuentes superficiales.

El arroyo presentaría una distribución de caudal de características comparables a las del río Miriñay, afectada por pulsos de crecidas. Los tributarios tienen un escurrimiento continuo durante la mayor parte del año, con caudales variables en función de los aportes pluviales y subterráneos. Muchos cauces se originan por aportes subterráneos ocasionados por la presencia de rocas de escasa permeabilidad cercanas a la superficie del terreno. Se estima que la cuenca del $\mathrm{A}^{\circ}$ Yaguarí produce un volumen medio anual escurrido a la salida de

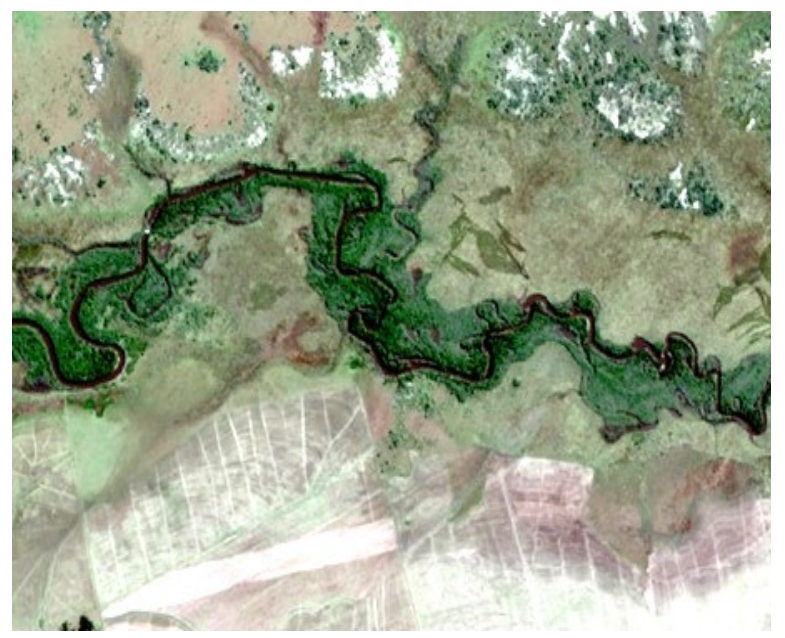

Figura 4. A: Cauce del $\mathrm{A}^{\circ}$ Yaguarí con patrón geomorfológico recto, abandono de antiguos meandros- $B$ : Cauce del $A^{\circ}$ Yaguarí con patrón geomorfológico meandriforme.

Figure 4. A: Linear geomorphological pattern along theYaguarí Creek-abandonment of ancient meanders-B: Meandering geomorphological pattern along the Yaguarí Creek.

lagunas de mayor permanencia temporal, incluso perennes. Otras geoformas dentro de la planicie de inundación que constituyen elementos de humedal diferenciables son pequeños canales de origen erosivo, alimentados por el flujo de inundación, que poseen cabeceras de patrón dendrítico desarrollada en la propia planicie.

\section{Aguas superficiales}

El $A^{\circ}$ Yaguarí recibe las aguas de varios tributarios: por margen derecha los $A^{\circ}$ Guayaibí, Aguay, Ibabiyú y Vaca Cuá, y por margen izquierda los $A^{\circ}$ Quebracho, Sarandí y Ombú (Fig. 1), que se alimentan por agua alrededor de $700 / 800 \mathrm{hm}^{3}$ (Guinzburg et al., 2014).

En noviembre de 2017 se muestrearon 9 puntos distribuidos de modo de capturar las condiciones fisicoquímicas y/o características de los cursos de agua de distinta jerarquía. En general, las aguas tienen baja turbiedad y salinización con conductividad eléctrica entre $44 \mu \mathrm{S} / \mathrm{cm}$ a $431 \mu \mathrm{S} / \mathrm{cm}$. Todas las muestras reflejan valores de concentración de la serie nitrogenada (Amonio, Nitritos, Nitratos) por debajo del límite de detección (Nessler, Colorimetría, Brucina), respectivamente. En su mayoría el pH está en torno a 7, con valores entre 6,69 y 8,07 . El sulfato también presenta valores por debajo del límite de detección $(10 \mathrm{mg} / \mathrm{L} \mathrm{-}$ método turbidimétrico). 


\section{Afectaciones-Represamientos}

Los procesos hidrológicos y la conectividad hidrológica de la cuenca han sido afectados por las actividades productivas: la producción de ganado bovino-ovino y de arroz. Ambas actividades requieren de la disponibilidad del recurso agua en cantidad y estacionalidad necesarias. Las mayores demandas del cultivo de arroz ocurren en el período estival, que se superponen con la de otros actores de la cuenca y la de los ecosistemas naturales. Por ende, se plantea un conflicto de naturaleza temporal, espacialmente distribuido en los tributarios laterales (Rujana y Currie, 2005).

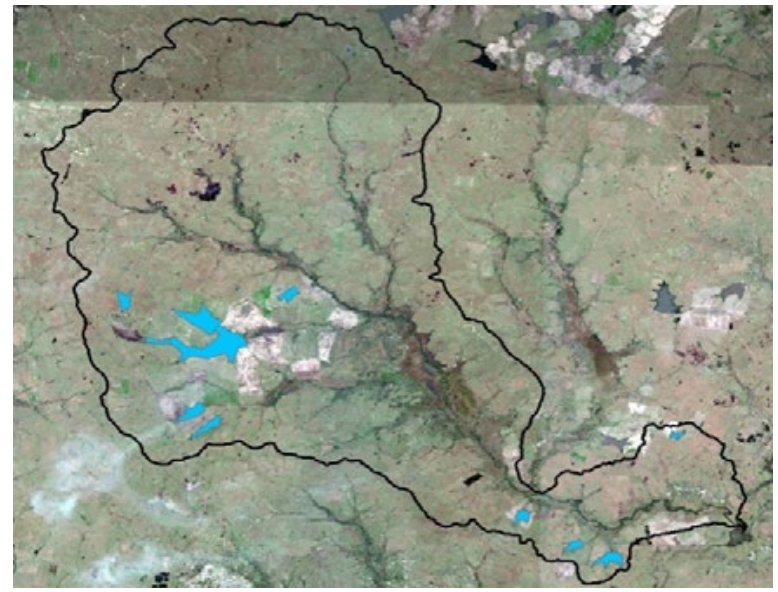

y una fotografía del lago formado por la represa más grande de la zona.

\section{Biodiversidad}

Corrientes es una de las provincias con mayor biodiversidad en Argentina (Rabinovich y Rapoport 1975, Giraudo et al., 2006), mostrando relevancia internacional por formar parte de un área mundial de endemismos para las aves denominada "Pastizales Mesopotámicos de Argentina", considerada significativa a nivel mundial por BirdLife International (Wege and Long, 1995), así como por la presencia de los remanentes más australes de la Selva Paranaense (Selva

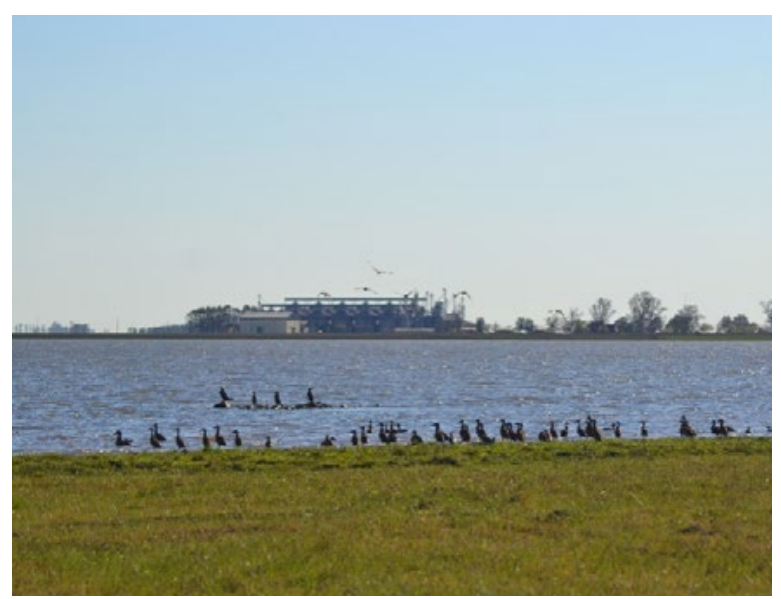

Figura 5. A: identificación de represamientos de tamaño variado (año 2016); B: lago formado por represa para cultivo de arroz. Figure 5. A: identification of reservoirs of varying sizes (year 2016). Bt: lake formed by earth dam for rice cultivation.

En los últimos 20-30 años se construyeron numerosas presas de tierra para regar por gravedad y/o bombeo, mediante el uso del agua embalsada, destinada a satisfacer la demanda de la superficie de arroz en expansión. Una geomorfologia apropiada, una abundante red de drenaje y cuenca de aporte suficientes contribuyeron a la implantación sostenida y creciente de estas obras en los principales afluentes del $A^{\circ} \mathrm{Ya}-$ guarí (Fig. 5).

El flujo de agua superficial de los arroyos y el flujo subsuperficial que se manifiesta en forma de manantiales son interrumpidos mediante la construcción de represas que permiten almacenar agua o bien para el abrevado animal (tajamares), o bien para riego. En la cuenca del $A^{\circ}$ Yaguarí, las obras se localizan preferentemente en cercanías de las nacientes de los afluentes, aprovechando la topografía del terreno. En algunos casos se observan varios represamientos a lo largo de un mismo tributario. El tamaño de los embalses es muy variable, poseen un largo mínimo de aproximadamente $100-150 \mathrm{~m}$ en la dirección del flujo del arroyo represado, hasta más de $5000 \mathrm{~m}$ de máximo desarrollo longitudinal. La Fig. 5 muestra la localización de represas/embalses de varios tamaños,
Atlántica), representada por selvas en galería en cursos fluviales, considerado uno de los "puntos calientes" (hotspots) de biodiversidad más amenazados del mundo (Myers et al., 2000).

El área de estudio se ubica en una región natural particular de Argentina, caracterizada por ser un área de transición entre climas tropicales y templados, y entre diferentes provincias biogeográficas como la Paranaense o Selva Atlántica (Dominio Amazónico), la Chaqueña, del Espinal y la Pampeana (del Dominio Chaqueño) (Giraudo y Arzamendia, 2018). La denominada ecoregión del Iberá por Burkart et al. (1999) es también periférica a la cuenca del Yaguarí hacia el norte. Cada una de estas regiones aporta elementos florísticos y faunísticos propios que se funden en un paisaje heterogéneo, observándose bosques semixerófilos con árboles chaqueños como el Guaraniná (Bumelia obtusifolia), que también contienen palmeras Pindó (Arecastrum romanzoffianum) propias de las selvas húmedas Paranaenses, y en sus bordes ejemplares de Ñandubay o Espinillo (Prosopis affinis), especie característica de los bosques del Espinal mesopotámico. Entre la fauna también coexisten elementos Paranaenses como el Arañero Silbador 
(Basileuterus leucoblepharus), chaqueños como la Bandurrita Chaqueña (Upucerthia certhioides), del espinal como el Cardenal Amarillo (Gubernatrix cristata, especie amenazada) y de la región Pampeana como son los Cisnes Coscoroba (Coscoroba coscoroba).

Los ambientes acuáticos están caracterizados por pajonales, pantanos y lagunas. Los ambientes lénticos están poblados por una densa comunidad vegetal, compuesta por una gran variedad de especies acuáticas, entre las que se distinguen grupos flotantes como los camalotales (Eichornia), los densos mantos de repollitos, lentejas, acordeones y helechos de agua (Pistia stratotes; Lemma spp, Salvinia y Azolla respectivamente), otras son flotantes arraigadas o de las oriIlas. Entre los vegetales arraigados, frecuentes en las orillas de los embalses y cuerpos lénticos, sobresalen exuberantes pajonales (Panicum spp.), pirizales (Scirpus y Cyperus), totorales (Tipha spp.), peguajosales (Thalia spp.), etc. que constituyen las comunidades de plantas palustres. La Fig. 6 ilustra algunas especies de flora y fauna de la zona.

La amplia heterogeneidad espacial se traduce en numerosos tipos de hábitats acuáticos y terrestres, la
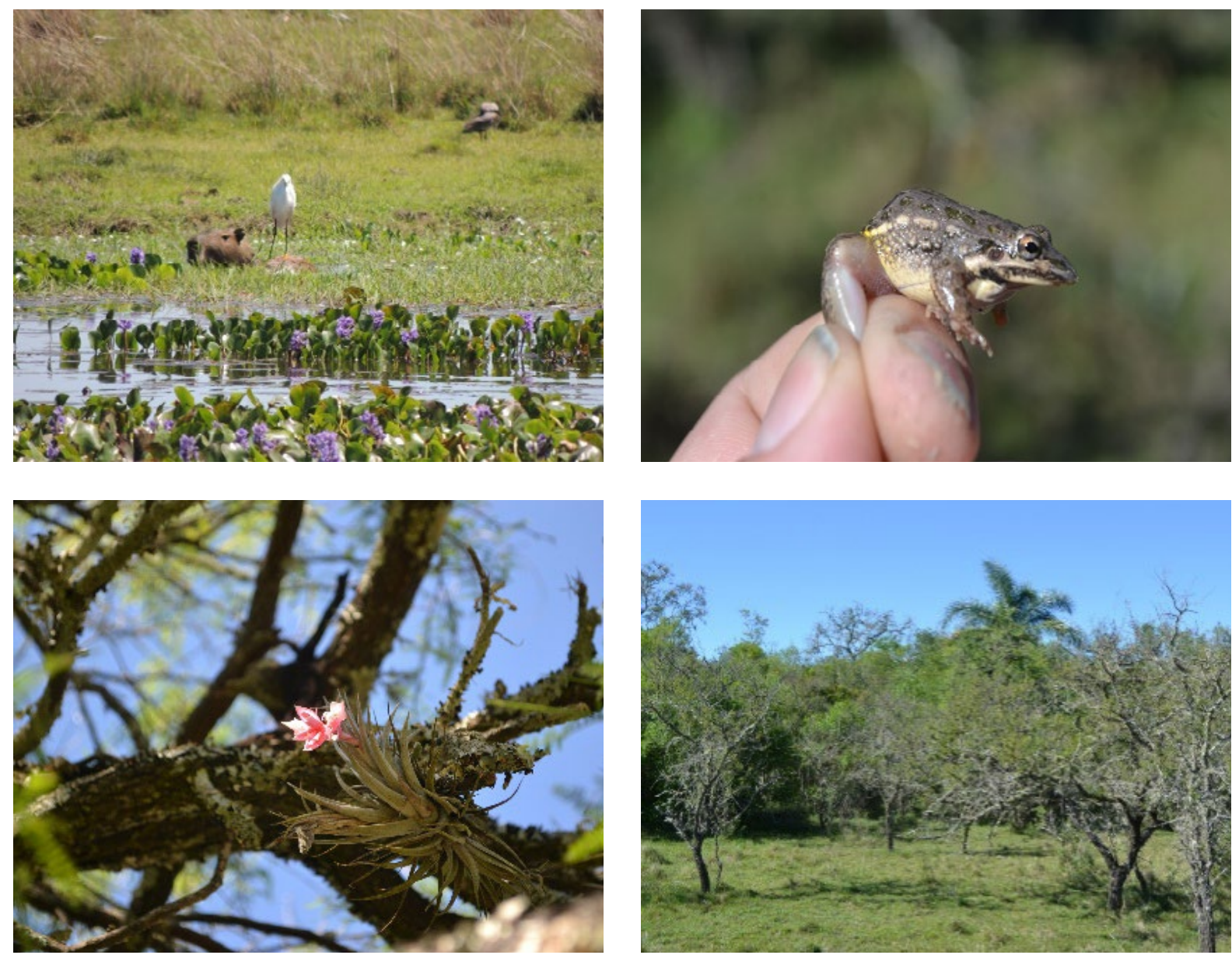

interfase entre ellos en muchos casos también constituye hábitats particulares. Los elementos florísticos y faunísticos, con elevada biodiversidad y especies amenazadas, se funden en un paisaje heterogéneo de hábitats acuáticos y terrestres.

\section{Amenazas}

Dentro del área estudiada se identificaron dos actividades que resultan a priori incompatibles con el mantenimiento de los ecosistemas de los humedales naturales relevados, estas son la ganadería extensiva y el cultivo de arroz e infraestructura asociada. Entre los impactos que causan se encuentran la pérdida y fragmentación de hábitat, y la introducción de especies exóticas, entre otras.

La actividad ganadera compite con los sistemas de humedales naturales, al demandar zonas aptas para el pastoreo de la ganadería vacuna y ovina. La demanda de áreas pastoriles ha ido en detrimento de sectores con bosque nativo, quedando, en la cuenca muy pocos sectores con bosques.

La necesidad de agua para consumo del ganado

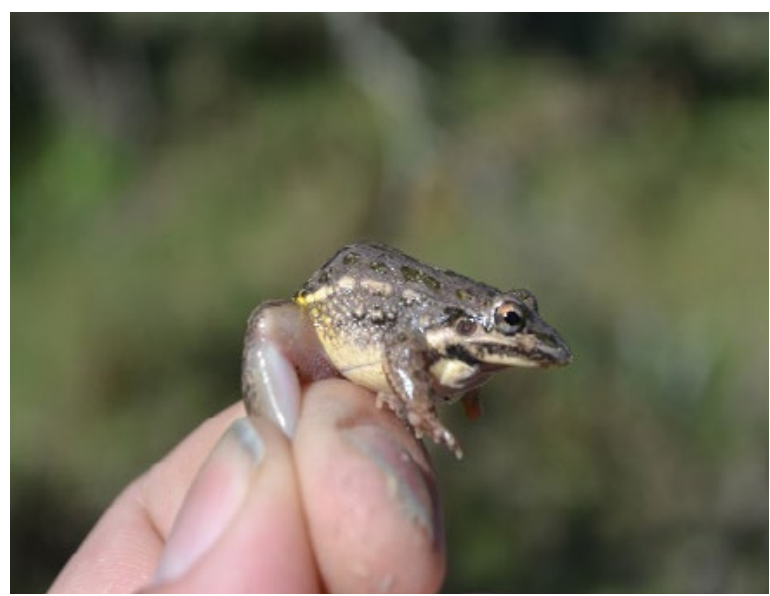

Figura 6. Especies de flora y fauna relevadas en la zona de estudio.

Figure 6. Flora and fauna species identified in the study region. 
provoca la intervención a través de construcción de tajamares en cauces menores, los que son interrumpidos con cierres mediante bordos de material suelto para embalsar y retener el agua. Otra práctica utilizada es el drenaje de los humedales de la planicie de inundación. La acción antrópica genera en el ambiente un cambio en las condiciones para el desarrollo de la vegetación, que se manifiesta gradualmente y parece acelerarse ante la incorporación de carga animal, se reemplaza la cobertura vegetal existente por pastos implantados.

Las áreas más buscadas para el cultivo del arroz son aquellas que se inundan naturalmente en algún periodo del año y/o poseen sustratos de baja permeabilidad cercanos a la superficie. Estas condiciones se presentan predominantemente en el entorno inmediato de los cursos de agua, en las zonas baja y media de la cuenca, donde se suelen drenar pantanos y bañados.

Por otro lado, los campos arroceros son irrigados con agua superficial por bombeo directo de los arroyos o a partir de embalses artificiales. Aunque estos últimos se transforman en verdaderos humedales artificiales, esta acción repercute negativamente en los sistemas fluviales cambiando drásticamente la dinámica hídrica natural, las características físico-químicas y limnológicas del agua y las comunidades acuáticas. La ausencia de legislación argentina que proteja los ambientes de humedal es sin duda una de las causas del avance del cultivo sobre las áreas pantanosas de las planicies de inundación.

\section{Metodología de identificación de los humedales}

En este trabajo se adoptó el Nivel 3 establecido por la SAyDS, en cuanto a la resolución espacial y a las variables de definición y caracterización utilizadas. Según este nivel, las unidades de humedal son entidades más o menos discretas localizadas en sitios particulares, con una tipología definida en términos de su emplazamiento geomórfico, el tipo de entradas y salidas del agua y el régimen hídrico.

La identificación de los tipos de humedal presentes en la cuenca del $\mathrm{A}^{\circ}$ Yaguarí se realizó a partir de cuatro aspectos independientes entre sí: 1) el conocimiento general surgido del análisis de antecedentes del área y de áreas geomorfológicamente similares, esto es, paisajes de modelado predominantemente fluvial estructurado en una red de drenaje; 2) la interpretación visual de imágenes satelitales, con análisis de fotoelementos (tono, patrón, textura, posición topográfica) distintivos de áreas de humedal y geoformas asociadas; 3) la identificación de momentos hidrológicos húmedos (por pluviosidad e inundación fluvial) y selección de imágenes satelitales a fin de verificar áreas de humedal interpretadas en (2); y 4) la identificación por observación directa del humedal en campo, con descripción de su geomorfología/geología, suelos, indicadores de calidad de agua y biodiversidad. Estos aspectos fueron luego integrados para definir los ti- pos de humedales en el marco de una clasificación de humedales simple, jerárquica y abierta, establecer la extensión espacial de los mismos, y caracterizar sus rasgos distintivos a escala del terreno.

El análisis de ciertas variables se realizó a través de un enfoque multi-escala de acuerdo a la disponibilidad de imágenes satelitales de diferentes sensores remotos. La escala de trabajo cartográfico fue 1/50.000, contando con imágenes con resolución espacial igual o mayor a $15 \mathrm{~m}$. Para la identificación de humedales se revisaron imágenes disponibles en la base de datos de CONAE (Comisión Nacional de Actividades Espaciales de Argentina). De ellas se seleccionaron escenas obtenidas en invierno / verano, para detectar la máxima expresión espacial del humedal. Para el reconocimiento de las unidades de humedal se dispuso de una cobertura completa de imágenes satelitales de la cuenca del $A^{\circ}$ Yaguarí, principalmente a escalas $1 / 100000$ (Landsat) y $1 / 50000$ (SPOT). En primer término, se observaron las imágenes Landsat para detectar los rasgos generales visibles del paisaje. A partir de la interpretación de las imágenes SPOT y un modelo digital de elevación, se marcó el contorno de la cuenca. La red de drenaje fue interpretada y delimitada comenzando con los elementos lineales correspondientes a los cursos principales, de orden 4 o 5 (según Strahler, 1957), continuando con los de menor orden finalizando con los tributarios de las cabeceras de la cuenca (orden 1). Luego se marcaron los elementos de área tales como planicies de inundación, embalses para riego y otros. Posteriormente, el trabajo de campo permitió confrontar y validar las unidades de humedal cartografiadas con lo visualizado en terreno, donde se realizó una constatación visual de la cartografía, se tomaron puntos de control temático y fotografías. Las muestras de suelo y aguas recolectadas fueron posteriormente analizadas en laboratorio.

\section{Clasificación e inventario de los humedales de la cuenca}

De la revisión de metodologías de clasificación disponibles surge que una característica común de varios sistemas de clasificación es su estructura jerárquica definida en base a aspectos geomorfológicos, hidrológicos y bióticos que caracterizan a los humedales. Según sean los aspectos considerados, resultan diferentes propuestas de clasificación que incluyen un nivel general de sistemas y subsistemas, y luego niveles más desagregados que comprenden clases, subclases y tipos dominantes de humedales.

La cuenca fluvial estudiada, designada como sitio piloto por la SAyDS, fue analizada según el Nivel 3 de inventario. La cuenca pertenece a la Subregión 5c: Malezales, tembladerales y arroyos litoraleños, descrita en las Regiones de umedales de Argentina (Benzaquén et al., 2017).

De acuerdo al análisis de antecedentes, y consi- 
derando las características del área de estudio en el contexto de la regionalización nacional (Benzaquén et al., 2017), la identificación de los tipos de humedal presentes en la cuenca del $\mathrm{A}^{\circ}$ Yaguarí se realizó utilizando una estructura de clasificación de humedales simple, jerárquica y abierta, cuyos componentes son: Ambiente-Región - Sistema - Unidad-Elemento.

El término fundamental de la clasificación es el Elemento, que identifica el bajío o área de drenaje retardado/impedido que constituye el humedal propiamente dicho, una combinación de emplazamiento geomorfológico e hidrología que permite o potencia el desarrollo de una biota diversa y característica.

Dado que la geoforma suele ser el componente antecedente y de considerable persistencia temporal, se adoptó la taxonomía de geoformas de Verstappen y Van Zuidam (1991) para identificar elementos. Así, los elementos de humedal propios de paisajes fluviales como el estudiado son: los pantanos tras-albardón, los cauces abandonados o paleocauces, los bajíos entre albardones, etc. Los humedales en albardones y albardones con derrames fueron considerados por la particularidad de sostener bosques en galería antes que como geoformas, ya que aquellos son elementos positivos del relieve con humedales sólo por su proximidad a los cuerpos de agua (cauces activos o abandonados). Dado que estos elementos pueden repetirse en un área geográfica definida constituyen, asociados, una Unidad de humedal, que es el cuarto término jerárquico de la clasificación. Un claro ejemplo de ello es la planicie de inundación, donde coexisten varios de los elementos nombrados en el párrafo previo, repitiéndose con regularidad en ese espacio en lo que concierne a sus dimensiones, composición y morfología.

El tercer término de la clasificación (Sistema) agrupa a los humedales de un área según su interrelación dominante (Fluvial, en el caso estudiado; otros sistemas de humedal en tal nivel son el Lagunar, Palustre, según la clasificación propuesta por Cowardin et al., 1979). Por sus particularidades de diseño y manejo, los humedales originados por acciones humanas son considerados como Sistemas Antrópicos. Este tipo de humedales están contemplados en la definición de humedales establecida en la Convención Ramsar (Davis, 1994).

La Región corresponde a la reciente delimitación de regiones mayores realizada por Benzaquén et al. (2017), y contextualiza a los Sistemas en estas áreas que los agrupan por su afinidad (u homogeneidad) fisiográfica.

Finalmente, el término primario de la clasificación corresponde al ámbito geográfico mayor de inserción del humedal, esto es, los dos tipos de Ambientes regionales clásicamente reconocidos: el netamente Continental, y el de transición a mares y océanos, i.e., el Costero.

La Tabla 1 resume la variedad de humedales reconocidos en la cuenca bajo estudio. Las unidades des- criptas en la Tabla 1 presentan variedades de acuerdo a rasgos intrínsecos de los elementos que los componen, algunos de los cuales fueron descritos en la sección de Geología. En los Humedales de Cabeceras y Tributarios Menores, es dable observar algunas variantes, de acuerdo al espesor del material sedimentario en el fondo del valle o a la existencia o no de un cauce menor, que facilite el drenaje del área; con sus variaciones, los humedales de cabecera son los menos diversificados en vegetación, predominando especies herbáceas de menor porte. Más aguas abajo, en el contexto del sistema fluvial, la contribución de varios valles y su aumento en orden da lugar a la aparición de los Corredores Ribereños. Estos están inmersos en amplios fondos planos de valle que no llegan a ser inundados por los cursos fluviales, y que carecen de vegetación hidrófita en toda su extensión, excepto a la vera de los cauces, donde se desarrollan bosques en galería. Finalmente, el humedal de Planicie de Inundación es el ecosistema más diversificado de todos, dada la variedad de elementos geomorfológicos, sustratos y tipos de escurrimientos que allí ocurren.

En cuanto a los Sistemas de Humedales Antrópicos, existen Unidades asociadas a las prácticas del cultivo de arroz y ganadería, respectivamente. Estas son las Arroceras y sus Embalses de Riego, y los Tajamares, vinculados a la producción ganadera de la región. Estos tipos de humedales antrópicos fueron listados por Frazier (1998). En la zona de estudio se mapearon extensas superficies destinadas al cultivo de arroz que permanecen inundadas durante al menos 90 días al año. Por lo tanto, este tipo de humedales son de carácter temporal, y si bien constituyen una oferta de hábitats por la disponibilidad de agua, pueden ser susceptibles a la colonización de especies exóticas y/o vectores de enfermedades (Schnack et al., 2000). Las zonas de almacenamiento de agua destinada al riego del arroz son de carácter permanente, y se interponen al flujo superficial, en ocasiones eliminando humedales naturales. Sin embargo, el perilago y zonas poco profundas de los reservorios suelen convertirse en nuevos hábitats para algunas especies de flora y fauna de la región (ver Fig. 5B).

\section{Fichas técnicas de caracterización y clasificación}

Se elaboraron fichas síntesis para cada unidad de humedal identificada, que provean una simple, clara y rápida descripción de la misma. Todas las fichas incluyen información sobre: a) Ubicación: localiza la cuenca de pertenencia y el lugar geográfico que ocupa dentro de la misma; b) Clima: presenta la clasificación climática, el climograma, la precipitación y la temperatura media anual, y el balance hídrico; c) Geología: identifica las Formaciones predominantes; d) Geoforma: describe el emplazamiento geomorfológico; e) Sustrato: describe el tipo de sedimentos que sustenta el humedal; f) Vegetación: enumera las especies 
watershed

\begin{tabular}{|c|c|c|c|c|}
\hline Ambiente & Región & Sistema & Unidad & Elementos \\
\hline \multirow{10}{*}{ Continental } & \multirow{10}{*}{$\begin{array}{l}\text { Corredor fluvial } \\
\text { Chaco } \\
\text { Mesopotámico }\end{array}$} & \multirow{7}{*}{ Fluvial } & \multirow{4}{*}{$\begin{array}{l}\text { Planicie de } \\
\text { inundación }\end{array}$} & Bosque en galería \\
\hline & & & & Pantano tras-albardón \\
\hline & & & & $\begin{array}{c}\text { Cárcavas/Surcos de } \\
\text { erosión }\end{array}$ \\
\hline & & & & Paleocauces \\
\hline & & & \multirow{2}{*}{$\begin{array}{c}\text { Cabeceras y } \\
\text { tributarios menores }\end{array}$} & Manantial \\
\hline & & & & Cauce \\
\hline & & & Corredor ribereño & Bosque en galería \\
\hline & & \multirow[t]{3}{*}{ Antrópico } & \multicolumn{2}{|c|}{ Embalse para riego } \\
\hline & & & \multicolumn{2}{|c|}{ Arrocera } \\
\hline & & & \multicolumn{2}{|c|}{ Tajamar } \\
\hline
\end{tabular}

Tabla 1. Estructura jerárquica propuesta para los humedales de la cuenca del $A^{\circ}$ Yaguarí.

Table 1. Hierarchical structure proposed for the wetland classification of the Yaguari Creek.

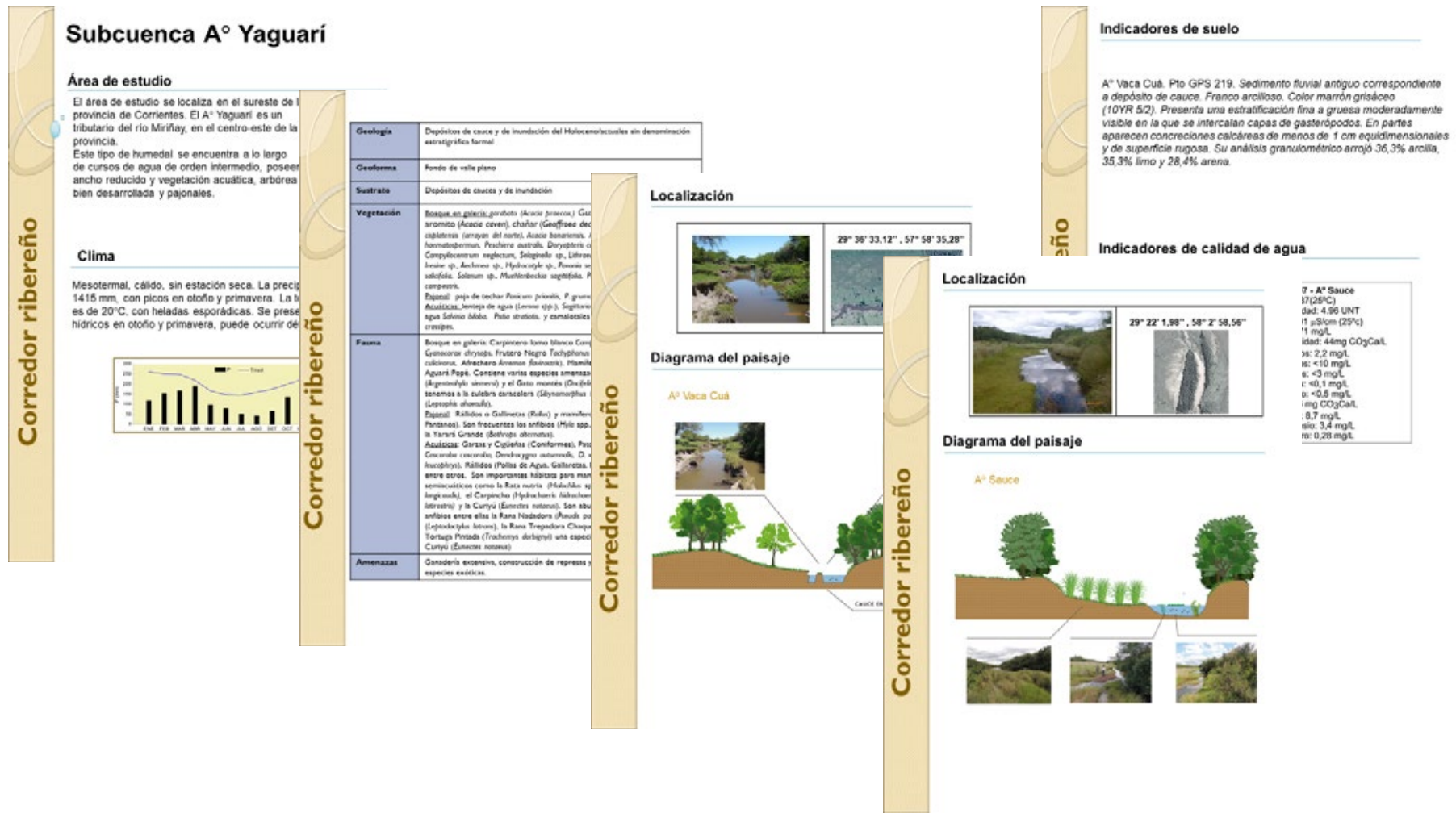

Figura 7. Ficha técnica de la unidad de humedal Corredor Ribereño.

Figure 7. Fact sheet of the riparian corridor wetland unit. 
dominantes; g) Amenazas: enumera los factores que ponen en riesgo la "salud" del humedal. Asimismo, las fichas incluyen un ejemplo concreto del tipo de humedal descrito, acompañado con indicadores de suelo y calidad de aguas, documentación fotográfica y un esquema del paisaje característico producto del relevamiento de campo realizado en cada uno. La Fig. 7 muestra un ejemplo de la ficha construida para la Unidad Corredor Ribereño.

\section{Conclusiones}

La metodología de clasificación propuesta a nivel de unidad de humedal- Nivel 3 de inventario, y su aplicación a una cuenca fluvial considerada como caso piloto, contribuye al esfuerzo que, desde la SMAyDS de Argentina, con la participación de ONGs y grupos de investigación, se viene realizando acerca del estudio e inventario de los humedales del país. El inventario de los humedales de la cuenca del $\mathrm{A}^{\circ}$ Yaguarí permitió realizar un mapeo de los mismos acompañado de una descripción detallada de sus aspectos físicos, químicos, ambientales, faunísticos y florísticos, servicios que brindan, usos de su entorno y amenazas. En base a antecedentes, análisis cartográfico, imágenes satelitales y verificación a campo, se identificaron humedales naturales de área, lineales y puntuales, a los que se suman diversos humedales antrópicos, asociados principalmente a explotaciones arroceras y pecuarias. Todos ellos se clasificaron mediante una estructura simple, jerárquica y abierta, siendo sus componentes Ambiente-Región-Sistema-Unidad-Elemento.

La provisión de agua para consumo de ganado y riego de arroz, constituyen los bienes y servicios de los humedales más reconocidos en la cuenca. De igual manera, estas actividades humanas amenazan a los sistemas naturales. Se manifiesta el avance del cultivo sobre las planicies de inundación, el uso de agroquímicos y la modificación de humedales mediante represamiento y derivación del agua.

La metodología desarrollada y aplicada en esta cuenca fluvial típica del noreste subtropical argentino, puede replicarse en cuencas de características similares de modo de contar con herramientas para el inventario, la evaluación y el manejo de los humedales del país. Además, podrá contribuir a construir un mejor entendimiento acerca de los diferentes tipos de humedales no solo por parte de la comunidad científico-técnica, sino por parte de los tomadores de decisión y propietarios de la tierra donde se encuentran los mismos.

\section{Agradecimientos}

A la Secretaría de Medio Ambiente y Desarrollo Sustentable de Argentina, por proveer los fondos para el desarrollo de este trabajo, a la Comisión Nacional de Investigaciones Espaciales de Argentina por la provisión de imágenes satelitales, a la Universidad Nacio- nal del Litoral en tareas de campo.

\section{Referencias}

Benzaquén, L., Blanco, D. E., Bó, R. F., Kandus, P., Lingua, G. F., Minotti, P., Quintana, R. y Vidal, L. 2013. Inventario de los humedales de Argentina: Sistemas de paisajes de humedales del Corredor Fluvial Paraná-Paraguay. Sec. de Amb. y Des. Sust. De Arg. Bs.As.

Benzaquén, L., Blanco, D.E., Bo, R., Kandus, P., Lingua, G., Minotti, P. y Quintana, R. (editores). 2017. Regiones de humedales de la Argentina. Ministerio de Ambiente y Desarrollo Sustentable, Fundación Humedales/Wetlands International, Univ. Nac. San Martín y UBA.

Brinson, M.M. 1993. A hydrogeomorphic classification for wetlands. Wetlands Research Program Technical Report WRP-DE-4. U.S. Army Corp of Engineers. 103 pp.

Brinson, M.M. 2008. Hydrogeomorphic wetland classification system: an overview and modification to better meet the needs of the Natural Resources Conservation Service. Natural Resources Conservation Service. Technical Note No. 190-8-76.

Burkart, R., Bárbaro, N.O., Sánchez, R.O. y Gómez, D.A. 1999. Ecorregiones de la Argentina. Administración de Parques Nacionales: Buenos Aires. Pp. 1-42 pp.

CONACYT-CONAGUA, 2012. Estudio interdisciplinario de los humedales de la República Mexicana: Desarrollo metodológico para el inventario nacional de humedales y su validación a nivel piloto. Metodología estandarizada para la evaluación de humedales en México a nivel de sitio, escala 1:20.000. Fondo Sectorial de Investigación y Desarrollo sobre el Agua Proyecto 84369. CONACYT-CONAGUA.

Costa L.T., Farinha, J.C., Hecker, N. and Vives, P.T. 1996. Mediterranean wetland inventory: A Reference Manual. MedWet/Instituto da Conservacao da Naturaleza/Wetlands International Publication. Volume I.

Cowardin, L.M., Carter, V., Golet, F.C. and LaRoe, E.T. 1979. Classification of wetlands and deepwater habitats of the United States, U.S. Department of Interior, Fish and Wildlife Service, Washington, DC. $131 \mathrm{pp}$.

Davis, T.J. (Editor). 1994. The Ramsar Convention Manual: A guide for the Convention on Wetlands of International Importance especially as waterfowl habitat. Ramsar Convention Bureau, Gland, Switzerland. $207 \mathrm{p}$.

Facultad de Ingeniería y Ciencias Hídricas-FICH, 2017. Inventario de humedales en sitios piloto. Subcuenca del $A^{\circ}$ Yaguarí. Provincia de Corrientes. Proponente: Ministerio de Ambiente y Desarrollo Sustentable, Argentina.

Finlayson, C.M., Begg, G.W., Howes, J., Davies, J., Tagi, K. and Lowry, J. 2001. A manual of an inven- 
tory of Asian Wetlands. Version 1.0. Wetlands International Global Series 10, Kuala Lumpur, Malasya.

Frazier, S. 1998. Visión general de los Sitios Ramsar. Una sinopsis de los Sitios Ramsar. Wetlands International, Convención Sobre los Humedales, Wageningen, Holanda. 42 pp.

Giraudo, A.R., Bortoluzzi, A. y Arzamendia, V. 2006. Vertebrados tetrápodos de la Reserva y Sitio Ramsar "Esteros del Iberá" (Corrientes, Argentina): Análisis de su composición y nuevos registros de especies amenazadas. Natura Neotropicalis 37:120

Giraudo, A.R. and Arzamendia, V. 2018. Descriptive bioregionalisation and conservation biogeography: what is the true bioregional representativeness of protected areas? Australian Systematic Botany, 30(6), 403-413.

Ginzburg, R.G., Menéndez, A.N., Torrella, S.A., Gerbec, M.S. y Adámoli, J. M. 2014. Estudio para definir los parámetros y criterios ambientales de la Cuenca del río Miriñay. Estudio realizado para el Instituto Correntino del Agua y el Ambiente. ICCAA. 110 pp.

Herbst, R. y Santa Cruz, J. 1985. Mapa litoestratigráfico de la Provincia de Corrientes. Revista d' Orbignyana-Corrientes 2: 1-51.

INTA-EEA Corrientes. Recursos Naturales. 2001. Suelos y vegetación de los departamentos Sauce y $\mathrm{Cu}$ ruzú Cuatiá, Provincia de Corrientes. 314 pp.

Junk W.J, Piedade M.T.F., Lourival, R., Wittmann, F., P. Kandus et al. 2014. Brazilian wetlands: their definition, delineation, and classification for research, sustainable management, and protection. Aquatic Conservation: Marine and Freshwater Ecosystems. 24: 5-22.

Mira A., Veroslavsky, G., Rossello, E., Vives, L. and Rodríguez, L. 2015. Subsurface geological modeling of Corrientes province (NE Argentina) and its influence in the Guaraní Aquifer System. Journal of South American Earth Sciences, 62, 148-163.

Mitch, W.J. and Gosselink, J. 2000. Wetlands. $3^{\text {rd }}$ ed. New York: John Wiley and Sons. 736pp.

Miteco (Ministerio para laTransición Ecológica), 2019. https://www.miteco.gob.es/es/biodiversidad/servicios/banco-datos-naturaleza/informacion-dispo- nible/inventario_esp_zonas_humedas_descargas. aspx, Acceso 20/1/2019.

Myres, N., Mittermeier, R.A., Mittermeier, C.G., da Fonseca, G.A.B., and Kent, J., 2000. Biodiversity hotspots for conservation priorities. Nature, volume 403, 853-858.

Rabinovich, J. and Rapoport, E. 1975. Geographical variation in the diversity of Argentine passerine birds. Journal of Biogeography. 2:141-57.

Ricaurte, L.F., Patiño, J.E., Zambrano, D.F.R. et al. 2019. A classification system for Colombian wetlands: an essential step forward in open environmental policy-making. Wetlands, 1-20. https://doi.org/10.1007/ s13157-019-01149-8

Rujana, M.R. y Currie, H.M. 2005. Estrategias de asignación y gerencia del agua en la cuenca del río Miriñay, Corrientes. Universidad Nacional del Nordeste, Argentina. Comunicaciones Científicas y Tecnológicas. 4 pp.

Schnack J.A, De Francesco1, F.O., Colado, U.R., Novoa, M.L. y Schnack, E.J. 2000. Humedales antrópicos: su contribución para la conservación de la biodiversidad en los dominios subtropical y pampásico de la Argentina. Ecología Austral, 10:63-80.

Scott, D.A. (compiler) 1989. A directory of Asian wetlands. IUCN, Gland, Switzerland and Cambridge, United Kingdom.

Strahler, A.N. 1957. Quantitative analysis of watershed geomorphology. EOS, Transactions American Geophysical Union, 38(6), 913-920.

Verstappen, H.Th. and Van Zuidam, R.A. 1991. The ITC System of Geomorphologic Survey: A basis for the evaluation of natural resources and hazards. Pub. ITC No. 10, The Netherlands, 89 pp.

Wege, D.C. and Long, A.J. 1995. Key areas for threatened birds in the Neotropics. Bird Life International. Cambridge, U.K.

Wilen, B.O., Carter, V. and Jones, J.R. 1996. Wetland Mapping and Inventory. National Water Summary on Wetland Resources. United States Geological Survey Water Supply Paper 2425.

Recibido: julio 2019

Revisado: noviembre 2019

Aceptado: enero 2020

Publicado: marzo 2021 
